\title{
Aloimunidade contra antígenos HLA de classe I em pacientes com síndromes mielodisplásicas e anemia aplástica
}

\author{
Aloimmunity against HLA class I antigens in patients with myelodisplastic syndrome and \\ aplastic anemia
}

Daisy M. M. Arruda ${ }^{1}$

Silvia F. R. Silva ${ }^{2}$

Sônia L. Silva ${ }^{3}$

Maria Helena Pitombeira ${ }^{4}$

Henry H. Campos ${ }^{4}$

Rosa M. S. Mota

Talapala G. Naidu ${ }^{6}$

\begin{abstract}
As síndromes mielodisplásicas (SMD) e a anemia aplástica (AA) apresentam citopenias periféricas necessitando, com freqüência, de reposições transfusionais contínuas de concentrados de hemácias e/ou de concentrados de plaquetas. O objetivo do presente estudo foi verificar a ocorrência de anticorpos anti-HLA de classe I em pacientes portadores das SMD e AA atendidos no ambulatório de Hematologia do Hemoce/UFC. Foram analisados 110 pacientes, sendo $70 \mathrm{com}$ SMD e $40 \mathrm{com}$ AA. A pesquisa de anticorpos anti-HLA de classe I foi realizada frente a um painel (PRA), utilizando-se a técnica de microlinfocitotoxicidade dependente do complemento. Vinte $(28,6 \%)$ dos 70 pacientes com as SMD e 18 (45\%) dos 40 pacientes com AA desenvolveram anticorpos anti-HLA contra o PRA. Esses pacientes que receberam uma carga de antígenos estranhos advindos de múltiplas transfusões de vários doadores de CH e/ou CP, geralmente desenvolvem aloanticorpos contra os antígenos HLA presentes na superfície das plaquetas e dos leucócitos que contaminam esses concentrados. A produção desses anticorpos pode trazer sérias complicações para o tratamento dos pacientes com SMD e AA. As avaliações sistemáticas para detecção de anticorpos anti-HLA após a reposição transfusional podem ser valiosas para adoção de estratégias transfusionais mais adequadas para esta população de pacientes. Rev. bras. hematol. hemoter. 2008;30(1):18-23.
\end{abstract}

Palavras-chave: Síndromes mielodisplásicas; anemia aplástica; transfusão; antígenos HLA.

\section{Introdução}

As síndromes mielodisplásicas (SMD) e a anemia aplástica (AA) são doenças hematológicas que apresentam citopenias periféricas com desenvolvimento de manifestações clínicas importantes. ${ }^{1,2}$ A conduta terapêutica mais efi- caz usada para corrigir a anemia (por falha na produção de células hematopoéticas) e os fenômenos hemorrágicos em pacientes trombocitopênicos (associados à aplasia medular ou à diminuição da produção de plaquetas) é a reposição transfusional de concentrados de hemácias $(\mathrm{CH})$ e de plaquetas (CP), respectivamente. Entretanto, as terapias transfu-

\footnotetext{
${ }^{1}$ Professora auxiliar da Disciplina de Hematologia da Universidade de Fortaleza (Unifor). Coordenadora do Controle de Qualidade do Laboratório LabPasteur.

${ }^{2}$ Professora assistente da Disciplina de Imunologia da Unifor. Diretora do Laboratório de Histocompatibilidade e Imunologia de Transplantes do CPDHR da UFC.

${ }^{3}$ Professora adjunto da Disciplina de Fisiologia da Unifor. Médica da Unidade de Transplantes do Hospital Universitário Walter Cantídio da UFC. ${ }^{4}$ Professor titular de Clínica Médica da Faculdade de Medicina da UFC.

${ }^{5}$ Professora adjunto do Departamento de Matemática e Bioestatística da UFC.

${ }^{6}$ Professor titular de Imunologia da UFC. Coordenador do Mestrado de Patologia da UFC.
}

Trabalho realizado no Laboratório de Histocompatibilidade e Imunologia de Transplantes do Centro de Pesquisas em Doenças Hepato-Renais (CPDHR) da Universidade Federal do Ceará (UFC), Fortaleza-CE, Brasil.

Correspondência: Daisy Maria Meireles Arruda

Rua Monsenhor Catão 1200, Apto 1301

60175-000 - Fortaleza-CE - Brasil

Tel.: (85) 3261-2593/3281-5810/ 9996-3623 - Fax: (85) 3281-5810

E-mail: daisyloureiro@terra.com.br 
sionais são realizadas sem compatibilidade dos antígenos do Sistema HLA (leucocyte human antigen) entre receptor/doador, e a cada transfusão o paciente entra em contato com aloantígenos HLA diferentes dos seus, tornando-os aloimunizados. ${ }^{3}$

A aloimunização, com conseqüente produção de anticorpos dirigidos contra antígenos do Sistema HLA, pode levar o paciente politransfundido a desenvolver refratariedade e um inadequado aproveitamento às transfusões de plaquetas, prejudicando o resultado terapêutico. ${ }^{4}$ Cerca de $40 \%$ a $70 \%$ dos pacientes com doenças hematológicas, politransfundidos, desenvolvem este estado refratário imunedependente. ${ }^{5,6}$ Nos pacientes com AA, o estado refratário pode ocorrer em $75 \%$ dos pacientes devido à periodicidade das transfusões recebidas. ${ }^{4}$

O objetivo do presente trabalho é verificar a ocorrência de anticorpos anti-HLA de classe I em pacientes portadores das SMD e AA atendidos no Serviço de Hematologia do Hospital Universitário Walter Cantídio da Universidade Federal do Ceará. E identificando os pacientes aloimunizados, seja possível escolher uma melhor conduta transfusional.

\section{Casuística e Método}

No período de janeiro de 2002 a dezembro de 2004 foram analisadas 214 amostras de soros provenientes de 110 pacientes, sendo setenta (63,6\%) com diagnóstico de SMD e quarenta (36,4\%) com diagnóstico de AA, acompanhados no Ambulatório de Hematologia do Hospital Universitário Walter Cantídio da Universidade Federal do Ceará.

A média de idade dos setenta pacientes com SMD foi 64,4 \pm 17 anos, com variação de 29 a 94 anos, sendo que 28 (40\%) pertenciam ao sexo masculino e 42 (60\%) ao sexo feminino. Os quarenta pacientes com AA apresentavam média de idade de 37,5 \pm 16,6 anos, com variação de 18 a 70 anos, sendo que 24 (60\%) pertenciam ao sexo masculino e 16 (40\%) ao sexo feminino.

Os dados pessoais, clínicos e terapêuticos dos pacientes, incluindo o número de transfusões recebidas, foram obtidos através de busca ativa nos prontuários de cada paciente. Na ocasião da coleta da amostra de soro, todos os pacientes e/ou responsáveis foram informados dos propósitos do estudo, obtendo-se consentimento por escrito, em termos explicativos e claros quanto aos procedimentos, seguindose os preceitos ditados pela declaração de Helsinque. O projeto deste estudo foi aprovado pelo Comitê de Ética em Pesquisa da Universidade Federal do Ceará sob o nº 147/05.

A análise dos soros dos pacientes frente ao painel de reatividade (PRA) contra os antígenos do Sistema HLA de classe I foi realizada no Laboratório de Histocompatibilidade e Imunologia de Transplantes do Centro de Pesquisas em Doenças Hepato-Renais da Universidade Federal do Ceará.
As amostras de soros dos pacientes foram coletadas e estocadas em freezer a $-20^{\circ} \mathrm{C}$ até o momento da construção do PRA. Todos os soros foram tratados com dithiothreitol (DTT) para a determinação da classe do anticorpo (IgG e/ou IgM). O PRA foi realizado em duas etapas distintas: a primeira etapa ocorreu à distribuição de soros puros e tratados com DTT nas placas de Terasaki, e, na segunda, ocorreu à adição dos linfócitos $\mathrm{T}$ dos doadores de células do PRA.

A pesquisa de anticorpos anti-HLA de classe I, frente ao PRA, foi realizada utilizando-se a técnica de microlinfocitotoxicidade dependente do complemento. Para análise dos resultados do PRA foram tomados por base os padrões de reatividade contra PRA utilizados por Scornick ${ }^{7}$ : Padrão 0 (PRA=0\%) - expansão clonal mínima com ausência de produção de anticorpos (pacientes não alorreativos); Padrão 1 (PRA<50\%) - pacientes alorreativos, expansão clonal mínima ou significante na presença de estímulos freqüentes com produção de anticorpos em baixos títulos; e Padrão 2 com reatividade $\geq 50 \%$ contra o PRA - expansão clonal significante com produção de anticorpos persistentes do tipo IgG, mesmo na ausência de estímulos freqüentes. Os pacientes que apresentaram alorreatividade contra PRA foram testados pela metodologia ELISA-LAT ${ }^{\mathrm{M}}$ para confirmação da classe dos anticorpos (Classe I e/ou Classe II).

Para análise dos dados, os resultados dos padrões de reatividade contra PRA (Padrões 0, 1 e 2) foram relacionados ao número de transfusão, ao tipo de transfusão, ao uso de filtros leucodepletores (deleucotização) e ao tipo de medicação imunomoduladora recebida pelos pacientes.

Os resultados foram apresentados como média, desvio padrão e porcentagem. O teste exato de Fisher foi usado para comparar resultados de análises obtidos nos diferentes grupos. A significância estatística foi definida como $\mathrm{p}<0.05$.

\section{Resultados}

Dos 110 pacientes estudados, 72 (65,5\%) não apresentaram anticorpos anti-HLA (Padrão 0) nas amostras de soros analisadas frente ao PRA, e em 38 (34,5\%) pacientes foram detectados anticorpos anti-HLA (Padrão 1 e 2). Quando esta análise foi realizada em função da doença hematológica, observou-se que vinte $(28,6 \%)$ dos setenta pacientes com SMD e 18 (45\%) dos quarenta pacientes com AA desenvolveram anticorpos anti-HLA após a terapêutica transfusional (Padrão 1 e 2).

As tabelas 1 e 2 sumarizam as principais características dos pacientes com SMD e AA, respectivamente, correlacionando-as à ocorrência de aloimunização, padrão de reatividade contra PRA observada, de acordo com a idade, sexo, número de transfusões, tipo de transfusão, uso de filtros leucodepletores nos concentrados sangüíneos e terapia imunomoduladora.

A análise dos padrões de reatividade mostrou que nos pacientes não alorreativos (Padrão 0) do sexo feminino foi 
Tabela 1. Características clínicas dos pacientes com síndromes mielodisplásicas relacionadas com a aloimunização após análises do PRA

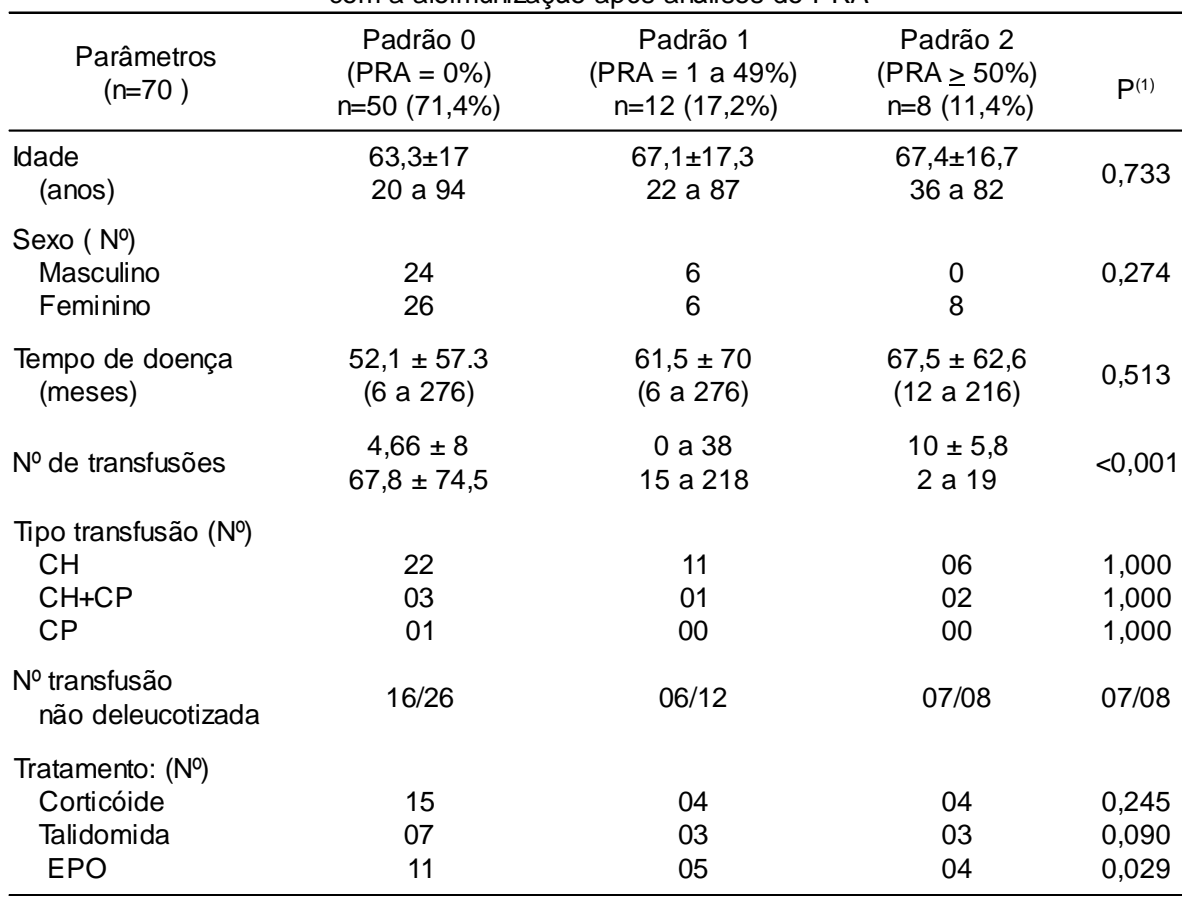

$\mathrm{N}^{\circ}=$ número de pacientes; $\mathrm{CH}=$ concentrado de hemácias; $\mathrm{P}=$ concentrado de plaquetas; EPO = eritropoetina. Resultados são expressos como média \pm desvio padrão ou número absoluto. Entre parênteses estão as porcentagens ou variações dos parâmetros analisados. (1) teste exato de Fisher

Tabela 2. Características clínicas dos pacientes com anemia aplástica de acordo com a reatividade contra painel de linfócitos (PRA)

\begin{tabular}{|c|c|c|c|c|}
\hline $\begin{array}{l}\text { Parâmetros } \\
\qquad N^{0}=40\end{array}$ & $\begin{array}{c}\text { Padrão 0 } \\
\text { (PRA = 0\%) } \\
\mathrm{n}=22(55 \%)\end{array}$ & $\begin{array}{c}\text { Padrão } 1 \\
\text { (PRA = 1\% a 49\%) } \\
n=08(20 \%)\end{array}$ & $\begin{array}{c}\text { Padrão 2 } \\
\text { (PRA } \geq 50 \%) \\
n=10(25 \%)\end{array}$ & $\mathrm{P}$ \\
\hline $\begin{array}{l}\text { Idade } \\
\qquad \text { (anos) }\end{array}$ & $\begin{array}{c}37,5 \pm 16,6 \\
(18-70)\end{array}$ & $\begin{array}{l}34,6 \pm 14,2 \\
(18-57)\end{array}$ & $\begin{array}{c}30,7 \pm 8,0 \\
(19-44)\end{array}$ & 0,267 \\
\hline $\begin{array}{l}\text { Sexo }\left(\mathrm{N}^{\circ}\right) \\
\text { Masculino } \\
\text { Feminino }\end{array}$ & $\begin{array}{l}12(30 \%) \\
10(25 \%)\end{array}$ & $\begin{array}{l}6 \\
2\end{array}$ & $\begin{array}{l}5 \\
5\end{array}$ & 0,900 \\
\hline $\begin{array}{l}\text { Tempo de doença } \\
\text { (meses) }\end{array}$ & $\begin{array}{c}74,1 \pm 78,7 \\
(11-312)\end{array}$ & $\begin{array}{c}36 \pm 26,8 \\
(12-84)\end{array}$ & $\begin{array}{c}73,1 \pm 52,8 \\
(11-180)\end{array}$ & 0,416 \\
\hline $\mathrm{N}^{\circ}$ de transfusões & $\begin{array}{l}77,7 \pm 42,8 \\
(21-197)\end{array}$ & $\begin{array}{c}66,7 \pm 34,6 \\
(21-135)\end{array}$ & $\begin{array}{c}86,5 \pm 46,6 \\
(25-197)\end{array}$ & 0,004 \\
\hline \multicolumn{5}{|l|}{ Tipo transfusão ( $\left.\mathrm{N}^{\circ}\right)$} \\
\hline $\begin{array}{l}\mathrm{CH} \\
\mathrm{CH}+\mathrm{CP} \\
\mathrm{CP}\end{array}$ & $\begin{array}{l}07 \\
09 \\
02\end{array}$ & $\begin{array}{l}02 \\
06 \\
00\end{array}$ & $\begin{array}{l}01 \\
09 \\
00\end{array}$ & $\begin{array}{l}1,000 \\
1,000 \\
0,121\end{array}$ \\
\hline $\begin{array}{l}N^{\circ} \text { transfusão } \\
\text { não deleucotizada }\end{array}$ & $12 / 18$ & $05 / 08$ & $08 / 10$ & 0,131 \\
\hline \multicolumn{5}{|c|}{$\begin{array}{l}\text { Tratamento } \\
\text { imunomodulador }\left(\mathrm{N}^{\circ}\right)\end{array}$} \\
\hline Corticóide & 11 & 06 & 09 & 0,046 \\
\hline CYA & 03 & 01 & 04 & 1,000 \\
\hline GAL & 031 & 04 & 01 & 0,430 \\
\hline
\end{tabular}

$\mathrm{N}^{\circ}=$ número; $p c t s$ = pacientes; $\mathrm{CH}=$ concentrado de hemácias; $\mathrm{CP}=$ concentrado de plaquetas; $\mathrm{CYA}=$ ciclosporina, $\mathrm{GAL}=$ globulina antilinfócitos. Resultados são expressos como média \pm desvio padrão ou número absoluto. Entre parênteses estão as porcentagens ou variações dos parâmetros analisados superior no grupo com SMD (57,2\%), enquanto no grupo com AA predominou o sexo masculino (82,5\%).

Em relação à idade dos pacientes não alorreativos contra o PRA em ambas as doenças ocorreu uma diferença significativa somente no grupo dos pacientes com SMD ( $\mathrm{p}=0,004)$. Quanto ao tempo de doença dos pacientes, não houve diferença significativa entre os dois grupos estudados quando comparados aos pacientes alorreativos dos mesmos grupos.

De acordo com o número de transfusões recebidas, observou-se uma diferença significativa entre os pacientes não alorreativos e alorreativos nos dois grupos estudados (SMD: $\mathrm{p}=0,038$ e AA: $\mathrm{p}=0,004$ ).

O padrão de maior reatividade (Padrão 2) em ambas as doenças foi observado naqueles de maior média transfusional $(\mathrm{SMD}=67,8 \pm 74,5 \mathrm{e}$ $\mathrm{AA}=86,5 \pm 46,6)$.

Dos cinqüenta pacientes com SMD não alorreativos, 26 (52\%) receberam transfusões, sendo que 22 (84,6\%) receberam apenas concentrado de hemácias $(\mathrm{CH})$, enquanto dos 22 pacientes com AA transfundidos, 11 (50\%) receberam concentrado de plaquetas (CP).

Dos 48 pacientes transfundidos, 26 com SMD e 22 com AA, 16 (51,5\%) e 12 (66,6\%), respectivamente, receberam $\mathrm{CH}$ e/ou $\mathrm{CP}$ sem nenhum tratamento leucodepletor.

Vinte e oito dos cinqüenta pacientes com SMD receberam tratamento com corticóide, talidomida e eritropoetina, enquanto 14 dos 22 pacientes com AA receberam corticóide, ciclosporina e globulina antilinfocitária, combinados ou isoladamente. Em relação ao tratamento, os pacientes com SMD que receberam eritropoetina obtiveram uma resposta mais efetiva na não produção de aloanticorpos anti-HLA ( $p=0,029)$, o mesmo ocorrendo com os pacientes com AA em relação ao corticóide $(p=0,046)$.

A classe dos anticorpos antiHLA, o isotipo e as especificidades 
Tabela 3. Caracterização dos anticorpos anti-HLA em pacientes com síndromes mielodisplásicas alorreativos

\begin{tabular}{|c|c|c|c|c|c|c|}
\hline \multirow[t]{2}{*}{ PRA } & \multicolumn{2}{|c|}{$\begin{array}{c}\text { Classe de anticorpos } \\
\text { anti-HLA }\end{array}$} & \multicolumn{3}{|c|}{$\begin{array}{l}\text { Isotipos dos } \\
\text { anticorpos anti-HLA }\end{array}$} & \multirow{2}{*}{$\begin{array}{c}\text { Especificidade } \\
\text { dos anticorpos } \\
\text { anti-HLA de Classe I }\end{array}$} \\
\hline & Classe I & $\begin{array}{l}\text { Classe I e } \\
\text { Classe } 2\end{array}$ & $\lg M$ & $\begin{array}{l}\operatorname{lgM} e \\
\lg G\end{array}$ & $\lg G$ & \\
\hline $\begin{array}{c}\text { Padrão } 1 \\
(\mathrm{n}=12)\end{array}$ & 8 & 4 & 8 & 3 & 1 & $A 2, A 23, A 24, B 7$ e $B 8$ \\
\hline $\begin{array}{l}\text { Padrão } 2 \\
(\mathrm{n}=8)\end{array}$ & 2 & 6 & 0 & 2 & 6 & $\mathrm{~A} 1, \mathrm{~A} 2, \mathrm{~A} 3, \mathrm{~A} 11, \mathrm{~A} 24$ \\
\hline
\end{tabular}

Tabela 4. Caracterização dos anticorpos anti-HLA em pacientes com anemia aplástica alorreativos

\begin{tabular}{|c|c|c|c|c|c|c|}
\hline \multirow[t]{2}{*}{ PRA } & \multicolumn{2}{|c|}{$\begin{array}{c}\text { Classe de anticorpos } \\
\text { anti-HLA }\end{array}$} & \multicolumn{3}{|c|}{$\begin{array}{c}\text { Isotipos dos } \\
\text { anticorpos anti-HLA }\end{array}$} & \multirow{2}{*}{$\begin{array}{c}\text { Especificidade } \\
\text { dos anticorpos } \\
\text { anti-HLA de Classe I }\end{array}$} \\
\hline & Classe I & $\begin{array}{l}\text { Classe I e } \\
\text { Classe } 2 \\
\end{array}$ & $\lg M$ & $\begin{array}{l}\lg M \text { e } \\
\lg G\end{array}$ & $\lg G$ & \\
\hline $\begin{array}{l}\text { Padrão } 1 \\
(\mathrm{n}=8)\end{array}$ & 7 & 1 & 3 & 0 & 5 & $\begin{array}{c}\text { A2, A23, A24, B8 } \\
B 44, B 62 \text { e B65 }\end{array}$ \\
\hline $\begin{array}{c}\text { Padrão } 2 \\
(\mathrm{n}=10)\end{array}$ & 4 & 6 & 0 & 1 & 9 & $\begin{array}{c}A 1, A 2, A 3, A 11, A 24 \\
\text { e } B 60\end{array}$ \\
\hline
\end{tabular}

menor tempo de doença (54,6 \pm 60,8 meses) e a menor média transfusional (12,7 $\pm 32,9$ unidades). Ressalte-se, ainda, que 84,6\% (22/26) desses pacientes receberam somente transfusões de concentrados de hemácias $(\mathrm{CH})$, com menor contaminação leucocitária, portanto menor capacidade de induzir respostas aloimunes. ${ }^{12}$ Sabe-se que os concentrados de plaquetas (CP) contribuem com uma maior carga antigênica, pois os mesmos são preparados partir de 8 a 10 unidades de sangue, provenientes de doadores aleatórios, além da contaminação leucocitária. ${ }^{8}$ Este procedimento pode ter influenciado na maior taxa de produção de aloanticorpos observada no grupo dos pacientes com AA (45\%), considerando que, dos 36 pacientes transfundidos, 26 (72,2\%) receberam CP associados ou não aos $\mathrm{CH}$.

O percentual de pacientes com SMD e AA que receberam transfusões de $\mathrm{CH}$ e/ou $\mathrm{CP}$ não deleucotizados, em algum período de seu tratamento, foi semelhante (SMD=63,0\% e AA=69,4\%), contribuindo para a ocorrência de aloimunização nesses pacientes. Diferentes estudos clínicos têm indicado que o uso de componentes sangüíneos dos anticorpos anticlasse I encontrados nos pacientes com SMD e AA são mostrados nas tabelas 3 e 4 . Foi observado que os pacientes que apresentaram uma maior faixa de aloimunização (Padrão 2) produziram anticorpos do tipo IgG, enquanto os de mais baixa reatividade (Padrão 1) produziram mais anticorpos do tipo IgM.

\section{Discussão}

Pacientes hematológicos que necessitam de reposição transfusional freqüente, seja de $\mathrm{CH}$ e/ou CP, tornam-se alvos preferenciais ao desenvolvimento do estado de refratariedade às transfusões, em conseqüência da aloimunização pós-transfusional. A aloimunização ocorre, na maioria dos casos, devido à presença de leucócitos contaminantes nos hemoderivados. Os antígenos HLA alogênicos das células do doador estimulam o sistema imune do paciente a produzir aloanticorpos antiplaquetários específicos, principalmente contra as moléculas HLA de classe I. ${ }^{8,9}$ Estudos realizados com pacientes trombocitopênicos politransfundidos, mostraram taxas de incidência de aloimunização variando de $35 \%$ a $90 \% .^{10,11}$

A análise dos soros dos 110 pacientes mostrou uma alorreatividade contra antígenos do Sistema HLA em 28,6\% dos pacientes portadores das SMD, portanto próximo ao menor valor dos dados da literatura. Por outro lado, mostraram-se concordantes no subgrupo dos pacientes com AA, que apresentaram $45 \%$ de alorreatividade. ${ }^{10,11}$

A baixa prevalência de alorreatividade observada nos pacientes com SMD pode estar relacionada a dois fatores: o leucodepletados poderia prevenir reações febris e diminuir ou prevenir aloimunização aos antígenos HLA e a refratariedade às transfusões de plaquetas. ${ }^{13-16}$

A aloimunização não foi observada em 71,4\% dos pacientes com SMD e em 55\% dos pacientes com AA. A alta taxa de não aloimunização (Padrão 0) observada nos pacientes com SMD pode ser explicada pelo fato de que esses pacientes apresentaram uma menor média transfusional do que os pacientes com AA (4,66 \pm 8 versus 77,7 $\pm 42,8)$. Além disso, os pacientes com SMD receberam mais $\mathrm{CH}$ (menos imunogênico), sendo que parte desses $\mathrm{CH}$ eram deleucotizados $(38,4 \%)$ e, também, pelo tipo de tratamento imunomodulador (corticóide, talidomida e eritropoetina) aplicado nesses pacientes. Entretanto, a não aloimunização observada em 55\% dos pacientes de AA, que apresentaram uma alta média transfusional, pode ter sido influenciada pelo uso de imunossupressores, pois $80 \%$ dos pacientes que receberam mais de dez transfusões fizeram ou estavam fazendo uso de terapia imunossupressora com corticóides, ciclosporina ou antiglobulinas no momento da análise do soro. De acordo com a literatura, pacientes com doenças hematológicas tratados com imunossupressores produzem menos respostas aloimunes do que os não tratados. ${ }^{17,18}$

O Padrão 1 (PRA<50\%) de aloimunização observado nas duas doenças revelou comportamento diferente, relacionado ao tempo médio de doença e número médio de transfusões. Os pacientes com AA apresentaram menor tempo médio de doença ( $36 \pm 26$,8 meses) e receberam maior número médio de transfusões $(66,7 \pm 34,6)$, enquanto os pacientes com SMD com maior tempo médio de doença (61,5 \pm 70 me- 
ses) apresentaram menor média transfusional $(10 \pm 5,8)$. Esta diferença no número de transfusões administradas nos dois grupos de pacientes se relacionou com os quadros de aloimunização nesses grupos com PRA $<50 \%$. Na literatura não foram encontrados dados de incidências de alorreatividade para cada uma das doenças estudadas. Somente um relato indireto da incidência de anticorpos anti-HLA, em pacientes portadores de AA, que apresentavam uma taxa de refratariedade às transfusões de plaquetas de $34 \%$, na qual a principal causa foi atribuída à aloimunização nesse grupo, que recebeu mais de 40 unidades de plaquetas. ${ }^{19}$

Os pacientes com AA (Padrão 1) que receberam de 21 a 135 transfusões com PRA $<50 \%$, de acordo com Scornik, podem estar na fase de expansão clonal III de alorreatividade, na qual haveria produção significante de anticorpos IgG em baixos títulos, ${ }^{7}$ não sendo detectado por técnicas pouco sensíveis como a microlincitotoxicidade. Entretanto, esses pacientes que receberam mais de vinte transfusões fizeram ou estavam fazendo uso de corticóides e antiglobulinas (GAL ou AGT), contribuindo para um menor grau de alorreatividade avaliado no PRA.

É presumível que os pacientes com SMD e AA pertencentes ao Padrão 2 de alorreatividade se encontrassem altamente sensibilizados, pois apresentam anticorpos de natureza IgG persistentes e em altos títulos, mesmo sem estímulos constantes. Este achado vai de encontro com informações da literatura de que pacientes politransfundidos ( $>40$ transfusões) apresentam um maior grau de reatividade no PRA. Segundo Kekomaki ${ }^{20}$ e Contreras, ${ }^{21}$ pacientes hiperimunizados teriam uma maior probabilidade de desenvolver a refratariedade imunológica às transfusões de plaquetas, ocasionando maior causa de morbidade e mortalidade entre os pacientes hematológicos.

Vale salientar que todos os oito pacientes com SMD do Padrão 2 eram mulheres multíparas que apresentaram anticorpos IgG contra as moléculas HLA de classe I, com reatividade persistente no PRA, mesmo sem estímulos antigênicos permanentes. ${ }^{7}$ Dados da literatura mostram que, além das transfusões sangüíneas, as gestações prévias constituem as maiores fontes de imunização contra os antígenos do Sistema HLA. ${ }^{15,22-26}$ Desta forma, uma política transfusional diferenciada, como a utilização de filtros leucodepletores e transfusões plaquetárias por aférese, deve ser adotada em mulheres com história pregressa de múltiplas gestações, por serem pacientes naturalmente aloimunizadas.

Koeffler ${ }^{27}$ relata que as SMD acometem indivíduos acima de 60 anos e que apenas 25\% dos casos têm idade menor que 50 anos. Segundo Bauer, ${ }^{26}$ a imunosenescência se inicia por volta dos 50 anos e acomete mais indivíduos com mais de 65 anos. Considerando que o fenômeno de imunosenescência pode diminuir as respostas imunológicas dos indivíduos, este fato nos leva a imaginar que a hipoalorreatividade de alguns pacientes com SMD possa estar influenciada pelo declínio das atividades imunológicas, considerando que $80 \%$ dos pacientes tinham mais de 50 anos.

Estudos anteriores ${ }^{9,11,13}$ relataram que $20 \%$ a $50 \%$ dos pacientes aloimunizados poderão tornar-se refratários às transfusões de plaquetas. Entretanto, a aloimunização poderá ser diminuída ou adiada, se as seguintes medidas forem adotadas: diminuição do número de doadores de plaquetas aleatórias (pool de plaquetas por buffy-coat); realização de transfusões de plaquetas de doadores aleatórios por aférese em pacientes aloimunizados e com chance de transplante, efetuar transfusões de plaquetas por aférese de doadores selecionados com compatibilidade HLA. Caso estas práticas não sejam oportunas, num dado momento de seu tratamento, deve-se assegurar que, pelo menos, todos os produtos sangüíneos administrados aos pacientes hematológicos sejam deleucotizados. No presente estudo, dos 110 pacientes, cinqüenta $(45,4 \%)$ receberam transfusões de $\mathrm{CH}$ e/ou CP não deleucotizados em algum momento de seu tratamento, o que dificulta a avaliação da real fonte de aloimunização.

Os dados desta investigação demonstram que pacientes com SMD e AA transfundidos freqüentemente desenvolvem aloanticorpos contra antígenos do Sistema HLA, e esta aloimunização é influenciada pelo tipo e freqüência de transfusões de hemocomponentes. As avaliações sistemáticas para detecção de anticorpos anti-HLA após a reposição transfusional podem ser valiosas para adoção de estratégias transfusionais mais adequadas para esta população de pacientes, como as que se seguem abaixo:

- assegurar que os produtos sangüíneos administrados em pacientes hematológicos sejam deleucotizados;

- diminuição do número de doadores de plaquetas aleatórios (pool de plaquetas por buffy-coat);

- realização de transfusões de plaquetas de doadores aleatórios por aférese em pacientes aloimunizados e com chance de transplante (excluindo seu doador);

- efetuar transfusões de plaquetas por aférese de doadores selecionados com compatibilidade HLA nos casos de pacientes hiperimunizados.

- realização da análise dos soros dos pacientes frente ao painel de reatividade (PRA) contra os antígenos do Sistema HLA de classe I após 10 a 15 de cada transfusão sangüínea para acompanhar a produção desses aloanticorpos.

\footnotetext{
Abstract

Patients with myelodysplastic syndromes (MDS) or aplastic anemia (AA) present peripheral cytopenias and require continuous transfusions of red cell and/or platelet concentrates. The objective of this study is to verify the existence of anti-HLA class 1 antibodies in patients with MDS and AA treated at the hematology Out patient Clinic of Hemoce/UFC. A total of 110 patients were analyzed, 70 with MDS and 40 with AA. Anti-HLA class 1 antibody detection was achieved with an antibody reactivity panel using the complement-dependent microlymphocytotoxicity technique. A total
} 
of 20 (28.6\%) of the 70 patients with MDS and 18 (45\%) of the 40 patients with AA developed anti-HLA antibodies against the antibody panel. In general, patients who received a load of foreign antigens originating from multi-donor red cell and platelet concentrate transfusions, developed alloantibodies against the HLA antigens that exist on the surface of platelets and on white blood cells that contaminate these concentrates. The production of these antibodies may cause serious complications in the treatment of MDS and AA patientss. Rev. bras. hematol. hemoter. 2008;30(1):18-23.

Key words: Myelodysplastic syndromes; aplastic anemia; transfusion; HLA antigens.

\section{Referências Bibliográficas}

1. Hofmann WF, Koeffler HP. Important features of myelodysplastic syndrome. Int J Hematol. 2002;76(suppl.2):222-7.

2. Young NS, Maciejewski J. The pathophysiology of acquired aplastic anemia. Massachusetts Med Society. 1997;336:1365-72.

3. Dausset J, Colombani J. Histocompatibility Testing, 1972.

4. Sivergleid AJ. Clinical platelet transfusion. In Silver H (ed): Blood, Blood Components and Derivatives in Transfusion Therapy. Washington DC, American Association of Blood Banks, 1980;45-88.

5. Schiffer CA, Dutcher JP, Hogge DE et al. Histocompatible platelet transfusion for patients with leukemia. Plasma Ther Trans Technol. 1982a;3:273.

6. Schiffer CA, Slichter SV. Platelet transfusion from single donors. N Engl J Med. 1982b;307:245.

7. Scornik JC, Brunson ME, Howard RJ, Pfaff WW. Alloimmunization, memory, and the interpretation of crossmatch results for renal transplantation. Transplantation. 1992;54:389-94.

8. Kickler TS. Platelet immunology. In: Anderson K, Ness PM (eds). Scientific Basis of Transfusion Medicine. WB Saunders; Philadelfia, PA, 1994;304.

9. Paula GG, Novaretti MC, Pozzi DHB, Chamone DAF. Study of the platelet refractiriness in patients submitted to bone marrow transplant from day 0 to day 50. Rev Bras Hematol Hemoter. 2004;26 (suppl 1):3-12.

10. Williamson LM, Wimperis JZ, Williamson P et al. Bedside filtration of blood products in the prevention of HLA alloimmunization - a prospective randomized study. Alloimmunisation Study Group. Blood. 1994;83 Suppl 10(15):3028-35.

11. Sintnicolaas K, Van Marwijk Kooij M, Van Prooijen HC, Van Dijk BA, Van Putten WL, Claas FH et al. Leukocyte depletion of random single-donor platelet transfusions does not prevent secondary human leukocyte antigen-alloimmunization and refractoriness: a randomized prospective study. Blood. 1995;85 Suppl 3(1):824-8.

12. Oksanen K, Kekomaki R, Ruutu $\mathrm{T}$ et al. Prevention of alloimmunization in patients with acute leukemia by use of white celldepleted blood components-a randomized trial. Transfusion. 1991; 31:588-94.

13. Slichter SJ. Platele refractoriness and alloimmunization. Leukemia. 1998;12(suppl 1):51-3.

14. Pietersz RN, Van Der Meer PF, Seghatchian MJ. Update on leucocyte depletion of blood components by filtration. Transfus Sci. 1998:19 (suppl 4):321-8.

15. Brand A, Claas FHJ, Voogt PJ et al. Alloimmunization alter leukocyte-depleted multiple random donor platelet transfusion. Vox Sang 1988;54:160-6.
16. Andreu G, Dewailly J, Leberre C et al. Prevention of HLA immunization with leucocyte-poor packed red cell and platelet concentrates obtained by filtration. Blood. 1988;72:964-9.

17. Dutcher JP, Linhxtenfeld JL, Wiernik PH. Long-follow-up of patients with leukemia receiving platelet transfusions: identification of a large group of patients who do not become alloimmunized. Blood. 1981;58:1007-11.

18. Rosenfeld SJ, Kimball J, Vining D, Young NS. Intensive immunosupression with antithymocyte globulin and cyclosporine as treatment for severe acquired aplastic anemia. Blood 1995; 85: 3058-65.

19. Klingemann HG, Self S, Banaji M et al. Refractoriness to randon donor platelet transfusion in patients with aplastic anemia: a multivariate analysis of data from 264 cases. Br J Haematol. 1987; 66:115-21.

20. Kekomäki S, Volin L, Koistinen P, Koivunen E et al. Successful treatment of platelet transfusion refractoriness: the use of platelet transfusions matched for both human leukocyte antigens (HLA) and human platelet alloantigens (HPA) in alloimmunized patients with leukaemia. Eur J Haematol. 1998;60:112-8.

21. Contreras M. Diagnosis and treatment of patients refractory to platelet transfusions. Blood Reviews. 1998;12:215-21.

22. Mueller-Eckhardt C. Histokompatibilität und Thrombozytentransfusion. Blut. 1980;34:261-70.

23. Terasaki PI, Mickey MR, Yamasaki JN, Vredevoe DL. Maternalfetal incompatibility. I. Induction of HLA antibodies and posible association with congenital anomalies. Transplantation. 1970; 9: 538-43.

24. Payne R, Rolfs MR. Fetomartenal leucocyte incompatibility. J Clin Invest 1958;37:1756.

25. Sirchia G, Parravicini A, Rebulla P et al. Effectiveness of red blood cells filtered through cotton wool to prevent (antileukocyte antibody production in multitransfused patients). Vox Sang. 1982; 42:190-7.

26. Bauer M. Chronic stress in caregivers of dementia patients is associated with reduced lymphocyte sensitivity to glucocorticoids. In J Neuroimmunology. 2000;103:84.

27. Koeffler HP. Myelodysplastic syndromes (preleukemia). Semin Hematol. 1986;23:284.

Avaliação: Editor e dois revisores externos

Conflito de interesse: sem conflito de interesses

Recebido: 15/09/06

Aceito após modificações: 15/03/07 